Revista Brasileira de Agricultura Irrigada v.10, nº.2, p. 496 - 506, 2016

ISSN 1982-7679 (On-line)

Fortaleza, CE, INOVAGRI - http://www.inovagri.org.br

DOI: $10.7127 /$ rbai.v10n200371

Protocolo 371.16 - 15/12/2015 Aprovado em 30/03/2016

\title{
REPOSIÇÃO HÍDRICA E ADUBAÇÃO COM NPK NO CRESCIMENTO E PRODUÇÃO DO FEIJOEIRO
}

\author{
Wilker Alves Morais ${ }^{1}$, Frederico Antonio Loureiro Soares ${ }^{2}$, Fernando Nobre Cunha ${ }^{3}$, Vitor \\ Marques Vidal $^{3}$, Nelmício Furtado da Silva ${ }^{3}$, Marconi Batista Teixeira ${ }^{4}$
}

\section{RESUMO}

No Brasil o feijão comum (Phaseolus vulgaris L.) representa uma importante fonte nutritiva para a população humana devido as suas características proteicas e energéticas. Objetivou-se avaliar as características de crescimento e produção do feijão (Phaseolus vulgaris L. var. BRS Estilo) submetidos a diferentes formulações de NPK e níveis de reposição hídrica. O delineamento experimental adotado foi de blocos casualizados, em parcelas subdivididas, onde as parcelas foram composta por quatro níveis de reposições hídricas (RH) $(100 ; 75 ; 50$ e $25 \%$ do recomendado) e as subparcelas por sete formulações de NPK, com base na dose recomendada, sendo 100:100:100; 50:100:50; 200:100:200; 50:100:100; 200:100:100; 100:100:50 e 100\%:100\%:200\% de N:P:K, com três repetições. Foram analisadas as seguintes variáveis: altura de planta (AP), número de folhas (NF), diâmetro de caule (DC), área foliar (AF), número de vagem por planta (NVP) e peso de grãos por planta (PGP). Quanto maior a disponibilidade de água para o feijoeiro melhor será os seus parâmetros quantitativos de crescimento (altura de planta, diâmetro do colmo, número de folha e área foliar) e produção (número de vagens por planta e produção de grãos por planta).

Palavras-chave: Nutrição mineral; déficit hídrico; Phaseolus vulgaris.

\section{WATER REPLACEMENT AND FERTILIZATION WITH NPK IN THE GROWTH AND BEAN PRODUCTION}

\begin{abstract}
In Brazil, the bean (Phaseolus vulgaris L.) is an important nutrient source for the human population due to their protein and energy characteristics. Objective was to evaluate the growth characteristics and production of beans (Phaseolus vulgaris L. var. BRS Estilo) submitted to different NPK formulations and water replacement levels. The experimental design was a randomized block, split plot, where the plots were composed of four levels of

\footnotetext{
${ }^{1}$ Doutorando em Ciências Agrárias - Agronomia, Instituto Federal Goiano - Campus Rio Verde, Rodovia Sul Goiana, Km 01, CEP: 75.901-170, Rio Verde - GO, e-mail: wilker.alves.morais@gmail.com

${ }^{2}$ Eng. Agrônomo, Prof. Dr. em Agronomia, IFGoiano - Campus Rio Verde, e-mail: fredalsoares@ hotmail.com

3 Doutorando em Ciências Agrárias - Agronomia, IFGoiano - Campus Rio Verde, e-mail: fernandonobrecunha@hotmail.com, vmarquesvidal@gmail.com, nelmiciofurtado@gmail.com

${ }^{4}$ Eng. Agrônomo, Prof. Dr. em Agronomia, IFGoiano - Campus Rio Verde, e-mail: marconibt@gmail.com
} 
water replacement $(100,75,50$ and $25 \%$ of recommended) and subplots seven NPK formulations, based at the recommended dose, 100:100:100; 50:100:50; 200:100:200; 50:100:100; 200:100:100; 100:100:50 and 100\%:100\%:200\% of N:P:K, with three replications. Were analyzed the following variables: plant height (AP), number of leaves (NF), stem diameter (DC), leaf area (AF), number of pods per plant (NVP) and grain weight per plant (PGP). The greater the availability of water for the bean better their quantitative parameters of growth (plant height, stem diameter, leaf number and leaf area) and production (number of pods per plant and grain weight per plant).

Keywords: Mineral nutrition; water deficit; Phaseolus vulgaris.

\section{INTRODUÇÃO}

No Brasil o feijão comum (Phaseolus vulgaris L.) representa uma importante fonte nutritiva para a população humana devido as suas características proteicas e energéticas (DAMIANI, 2011). Uma das principais fontes de alimentação da população brasileira, esta Fabacea é a quinta mais produzida no Brasil, ficando atrás apenas da soja, do milho, do arroz e do trigo (CONAB, 2015).

O feijão é uma cultura de elevado padrão de risco, devido à grande sensibilidade tanto ao déficit hídrico quanto ao excesso de água, tornando-se cada vez mais interessante a tecnificação da produção, utilizando-se de sistemas de irrigação e outras tecnologias, que promovam ganhos de produtividade (FIGUEIREDO et al., 2006).

Entre as deficiências nutricionais que ocorrem na cultura do feijão, a de $\mathrm{N}$ é a mais frequente, devendo-se precisar a dose e época corretas; o $\mathrm{N}$ por ser o nutriente mais absorvido e o mais exportado pelas plantas deve ser reposto, a propiciar boa nutrição a planta (SILVA et al., 2000; CARVALHO et al., 2001). Além do $\mathrm{N}$ o feijão-comum pode absorver, em condições favoráveis, quantidades significativas de potássio, proporcionando melhor desenvolvimento dos grãos na maturação e no vigor da semente (OLIVEIRA et al., 1996).

Para otimizar a produção de grãos se faz assim necessário o manejo adequado da fertilidade do solo aliado ao manejo adequado de irrigação, seja com novas tecnologias seja com métodos mais eficientes de uso dos recursos fertilizantes e água, com intuito de proporcionar uma colheita de grãos de melhor qualidade, maior produtividade em menor área cultivada e maior viabilidade econômica (FIGUEIREDO et al, 2008; FIGUERÊDO, et al, 2008; GOMES et al, 2012; MOUSINHO et al., 2008; SCHMIDT \& VALIATI, 2006).

Por tais motivos se torna importante os testes de adubações e irrigações para saber qual a melhor formulação e a melhor reposição hídrica para o melhor crescimento, desenvolvimento e produção de uma cultura. Diante deste contexto, objetivou-se avaliar as características de crescimento e produção do feijão (Phaseolus vulgaris L. var. BRS Estilo) submetidos a diferentes formulações de NPK e níveis de reposição hídrica.

\section{MATERIAL E MÉTODOS}

O experimento foi realizado em casa de vegetação climatizada no Instituto Federal Goiano - Campus Rio Verde, no Sudoeste de Goiás, localizada a $17^{\circ} 47^{\prime} 53$ ' de latitude Norte e $51^{\circ} 55^{\prime} 53^{\prime}$ ' de latitude Sul, a $743 \mathrm{~m}$ de altitude, o solo utilizado foi caracterizado com Latossolo Vermelho distroférrico (EMBRAPA, 2006). A temperatura média foi de $27^{\circ} \mathrm{C} \pm 3$, a umidade relativa média foi de $70 \% \pm 3$ e a velocidade do vento foi de $2,4 \mathrm{~km}$ $\mathrm{h}^{-1}$ quando o ventilador exaustor estava em movimento.

A casa de vegetação utilizada possui o sistema de climatização (temperatura e umidade) por circulação e refrigeração de água, aeração controlada por exaustores, sistema de irrigação por aspersores e cortina de sombreamento. Todos esses dispositivos são automatizados e são controlados por regulagem em seu painel de controle principal. 
O delineamento experimental adotado foi de blocos casualizados, em parcelas subdivididas, onde as parcelas foram composta por quatro níveis de reposições hídricas $(\mathrm{RH})$ (100; $75 ; 50$ e $25 \%$ do recomendado) e as subparcelas por sete formulações de NPK, com base na dose recomendada, sendo 100:100:100; 50:100:50; 200:100:200; 50:100:100; 200:100:100; 100:100:50 e 100\%:100\%:200\% de N:P:K, com três repetições.

Para adubação utilizou-se $0,68 \mathrm{~g}$ de nitrogênio $(\mathrm{N}), 2,4 \mathrm{~g}$ de fósforo $(\mathrm{P})$ e 1,2 $\mathrm{g}$ de potássio $(\mathrm{K})$ que para este trabalho equivalem a 100:100:100\% de NPK. Os outros tratamentos variaram com as demais porcentagens.

Para obter a irrigação recomendada utilizou-se três vasos drenos (lisímetro de drenagem) para cada $\mathrm{RH}$ que foi considerada as lâminas de $100 \%$. Nesses drenos foram adicionadas uma lâmina de água, até os vasos começarem a drenar. A água percolada encontrada nos coletores foi medida em uma proveta com volume conhecido $(500 \mathrm{~mL})$ precisão de $0,5 \mathrm{~mL}$, o valor encontrado foi subtraído a quantidade inicial irrigada, este procedimento foi feito para todos os nove lisímetros de drenagem onde em seguida foram obtidas suas médias. A quantidade retida no vaso foi considerada a recomendação e desses valores tinha-se as outras porcentagens de irrigação (75; 50 e $25 \% \mathrm{RH})$.

Instalou-se um sistema de irrigação por gotejamento na casa de vegetação com 12 registros, que foram utilizados para controlar a água que era inserida em cada vaso, sendo, um registro para cada tratamento e suas devidas repetições. O tubo gotejador foi disposto na parte superficial dos vasos onde cada vaso recebia água de um emissor. Antes da água chegar aos tubos gotejadores, esta passava por um manômetro de glicerina para regulagem da pressão.

Os vasos utilizados tinham capacidade para $10 \mathrm{~kg}$ porém foram devidamente preenchidos com $8 \mathrm{~kg}$ com solo (Latossolo Vermelho distroférrico).

Avaliou-se a altura de planta (AP), diâmetro do caule (DC), número de folhas
(NF) e área foliar (AF) aos 15, 30, 45, 60 e 75 dias após semeadura (DAS). A altura de planta foi medida da superfície do solo até o terceiro nó do feijoeiro, ambas medições foram realizadas com o auxílio de uma trena métrica.

O DC foi mensurado próximo a superfície do solo, com auxílio de paquímetro digital eletrônico do tipo "bico fino" (Ponta Aguda) com precisão de 0,01 mm ou 0005". Foram contadas apenas as folhas expandidas para NF. A AF foi calculada utilizando a equação recomendada por Figueiredo et al. (2012), onde $\mathrm{AF}=\Sigma 0,575 \mathrm{x}(\mathrm{CxL})$, sendo $\mathrm{C}$ e $\mathrm{L}$ o maior comprimento e a maior largura da folha, respectivamente, de todas as folhas expandidas do feijoeiro. Com relação a produção foram contadas o número de vagens por planta (NVP) e a produção de grãos por planta (PGP).

Os dados para cada variável foram submetidos à análise de variância pelo programa estatístico SISVAR (FERREIRA, 2011). Posteriormente, quando significados pelo teste $\mathrm{F}$, foram submetidos ao teste de Tukey a 5\% de probabilidade para os tipos de formulações de adubos e regressões para as reposições hídricas.

\section{RESULTADOS E DISCUSSÃO}

Na Tabela 1 observa-se o resumo da análise de variância para a altura de planta (AP), do feijoeiro submetidos as reposições hídricas (RH) de 100, 75, 50 e $25 \%$ e a diferentes tipos de formulações de adubações (F), sendo, 100:100:100; 50:100:50; 200:100:200; 50:100:100; 200:100:100; 100:100:50 e 100\%:100\%:200\% do recomendado para $\mathrm{N}: \mathrm{P}: \mathrm{K}$, avaliadas aos 15 , 30, 45, 60 e 75 dias após semeadura (DAS). Verifica-se que houve diferença significativa para a reposição hídrica nos 30, 45, 60 e 75 DAS. Não houve resultados significativos em nenhuma das épocas avaliadas, ou seja, apenas aos 45 DAS houve significância de $1 \%$ para a interação RH x F.

Abordando os resultados de diâmetro do caule (DC) do feijoeiro, constata-se na Tabela 1 que apenas na primeira avaliação (15 DAS) 
não houve resultados significativos para o fator RH. Isso pode ser explicado pelo fato das plantas ainda estarem novas para se constatar diferenças significativas para este fator. Os demais DAS mostraram significância a $1 \%$, indicando que as RH influenciaram no DC dos feijoeiros. Observando os resultados do fator $F$ (Tabela 1), verificou-se diferença significativa de $5 \%$ de probabilidade apenas aos 75 DAS. Leal e Prado (2008) verificaram que o potássio, seguido do fósforo e do nitrogênio, foi o elemento que mais afetou os parâmetros vegetativos de crescimento do feijoeiro.
No número de folhas (NF) do feijoeiro só foi constatada diferença significativa para o fator $\mathrm{RH}$ aos 30; 45 e 75 DAS (Tabela 1), para o fator $\mathrm{F}$ e interação RH x $\mathrm{F}$ não ocorreu diferença estatística em nenhuma das épocas avaliadas, mostrando que as formulações não interferiram no número de folhas do feijoeiro. Para a área foliar (AF) do feijoeiro, nota-se que houve diferença significativa de $1 \%$ de probabilidade aos 30; 60 e 75 DAS e de 5\% para os 45 DAS. Não se constatou diferença significativa para o fator $\mathrm{F}$ e a interação $\mathrm{RH} x$ F (Tabela 1).

Tabela 1. Resumo da ANAVA para altura de planta, diâmetro do caule, número de folhas e área foliar do feijoeiro submetido a diferentes reposições hídricas e tipos de formulações de adubação aos 15, 30, 45, 60 e 75 dias após semeadura (DAS).

\begin{tabular}{|c|c|c|c|c|c|c|}
\hline \multirow{2}{*}{ Fonte Variação } & \multirow{2}{*}{ GL } & \multicolumn{5}{|c|}{ Quadrados Médio } \\
\hline & & $15 \mathrm{DAS}$ & $30 \mathrm{DAS}^{1}$ & $45 \mathrm{DAS}^{1}$ & $60 \mathrm{DAS}^{1}$ & $75 \mathrm{DAS}^{1}$ \\
\hline \multicolumn{7}{|c|}{ Altura de planta ${ }^{1}$} \\
\hline RH & 3 & $0,68^{\mathrm{ns}}$ & $3,11^{*}$ & $35,34^{* *}$ & $13,81^{*}$ & $11,54^{*}$ \\
\hline Bloco & 2 & $2,77^{\mathrm{ns}}$ & $0,53^{\mathrm{ns}}$ & $11,04^{\mathrm{ns}}$ & $5,99^{\mathrm{ns}}$ & $12,34^{\mathrm{ns}}$ \\
\hline Resíduo a & 6 & 1,98 & 0,43 & 3,45 & 2,09 & 2,05 \\
\hline $\mathrm{F}$ & 6 & $0,27^{\mathrm{ns}}$ & $0,03^{\mathrm{ns}}$ & $1,29^{\mathrm{ns}}$ & $0,38^{\mathrm{ns}}$ & $0,46^{\mathrm{ns}}$ \\
\hline $\mathrm{RH} \times \mathrm{F}$ & 18 & $0,44^{\mathrm{ns}}$ & $0,08^{\mathrm{ns}}$ & $3,29^{* *}$ & $0,41^{\mathrm{ns}}$ & $0,48^{\mathrm{ns}}$ \\
\hline Resíduo b & 48 & 0,55 & 0,06 & 1,39 & 0,88 & 0,64 \\
\hline $\mathrm{CV}$ a $(\%)$ & & 19,65 & 14,45 & 21,56 & 15,53 & 14,82 \\
\hline $\mathrm{CV} b(\%)$ & & 10,42 & 5,64 & 13,71 & 10,09 & 8,34 \\
\hline \multicolumn{7}{|c|}{ Diâmetro do caule } \\
\hline RH & 3 & $0,07^{\mathrm{ns}}$ & $5,71^{* *}$ & $23,07^{* *}$ & $26,93^{* *}$ & $33,36^{* *}$ \\
\hline Bloco & 2 & $0,60^{\mathrm{ns}}$ & $1,07^{\mathrm{ns}}$ & $0,35^{\mathrm{ns}}$ & $0,58^{\mathrm{ns}}$ & $1,11^{\mathrm{ns}}$ \\
\hline Resíduo a & 6 & 0,04 & 0,50 & 0,74 & 1,57 & 2,19 \\
\hline $\mathrm{F}$ & 6 & $0,01^{\mathrm{ns}}$ & $0,14^{\mathrm{ns}}$ & $0,38^{\mathrm{ns}}$ & $1,12^{\mathrm{ns}}$ & $1,35^{*}$ \\
\hline $\mathrm{RH} \times \mathrm{F}$ & 18 & $0,01^{\mathrm{ns}}$ & $0,11^{\mathrm{ns}}$ & $1,20^{\mathrm{ns}}$ & $0,66^{\mathrm{ns}}$ & $0,63^{\mathrm{ns}}$ \\
\hline Resíduo b & 48 & 0,02 & 0,07 & 0,77 & 0,46 & 0,59 \\
\hline $\mathrm{CV}$ a $(\%)$ & & 7,07 & 12,84 & 12,51 & 16,32 & 18,46 \\
\hline $\mathrm{CV} \mathrm{b}(\%)$ & & 4,54 & 4,92 & 12,71 & 8,87 & 9,63 \\
\hline \multicolumn{7}{|c|}{ Número de folhas ${ }^{2}$} \\
\hline RH & 3 & & $21,72^{*}$ & $523,46^{* *}$ & $6,50^{\mathrm{ns}}$ & $9,18^{* *}$ \\
\hline Bloco & 2 & & $1,85^{\mathrm{ns}}$ & $108,44^{*}$ & $1,02^{\mathrm{ns}}$ & $2,26^{\mathrm{ns}}$ \\
\hline Resíduo a & 6 & & 2,66 & 17,26 & 1,90 & 0,84 \\
\hline $\mathrm{F}$ & 6 & & $0,99^{\mathrm{ns}}$ & $9,75^{\mathrm{ns}}$ & $0,55^{\mathrm{ns}}$ & $0,69^{\mathrm{ns}}$ \\
\hline $\mathrm{RH} \times \mathrm{F}$ & 18 & & $0,78^{\mathrm{ns}}$ & $11,64^{\mathrm{ns}}$ & $0,43^{\mathrm{ns}}$ & $0,72^{\mathrm{ns}}$ \\
\hline Resíduo b & 48 & & 0,69 & 14,34 & 0,28 & 0,66 \\
\hline $\mathrm{CV}$ a $(\%)$ & & & 19,46 & 20,24 & 26,21 & 21,53 \\
\hline $\mathrm{CV} b(\%)$ & & & 9,95 & 18,45 & 10,09 & 19,18 \\
\hline \multicolumn{7}{|c|}{ Área foliar ${ }^{1}$} \\
\hline RH & 3 & $97,13^{\text {ns }}$ & $75,50^{* *}$ & $688,64^{*}$ & $3477,97^{* *}$ & $3103,33^{* *}$ \\
\hline Bloco & 2 & $4,24^{\mathrm{ns}}$ & $12,45^{\mathrm{ns}}$ & $398,38^{\mathrm{ns}}$ & $128,62^{\mathrm{ns}}$ & $133,56^{\mathrm{ns}}$ \\
\hline Resíduo a & 6 & 292,06 & 6,83 & 124,70 & 125,83 & 223,92 \\
\hline
\end{tabular}


REPOSIÇÃO HÍDRICA E ADUBAÇÃO COM NPK NO CRESCIMENTO E PRODUÇÃO DO FEIJOEIRO

$\begin{array}{ccccccc}\text { F } & 6 & 105,82^{\text {ns }} & 9,46^{\text {ns }} & 48,38^{\text {ns }} & 72,01^{\text {ns }} & 136,28^{\text {ns }} \\ \text { RH x F } & 18 & 126,37^{\text {ns }} & 5,85^{\text {ns }} & 79,44^{\text {ns }} & 46,92^{\text {ns }} & 137,32^{\text {ns }} \\ \text { Resíduo b } & 48 & 145,88 & 4,78 & 56,97 & 35,60 & 107,05 \\ \text { CV a (\%) } & & 16,77 & 14,94 & 38,19 & 29,64 & 37,47 \\ \text { CV b (\%) } & & 11,85 & 12,50 & 25,81 & 15,77 & 25,91\end{array}$

${ }^{\text {ns }}$ teste $\mathrm{F}$ não significativo a $5 \%,{ }^{*} \mathrm{e}^{* *}$ significativo a 5 a $1 \%$ de probabilidade, respectivamente. GL - Grau de liberdade. RH - Reposição hídrica. F - Tipo de formulação. RH x F - Interação RH x F. CV - Coeficiente de variação. ${ }^{1}$ Dados transformados em Raiz de X. ${ }^{2}$ Dados transformados em Raiz de $\mathrm{X}+1$.

Nas épocas de avaliação, as plantas apresentaram crescimento linear a medida que aumentou-se a reposição hídrica (Figura 1A). De acordo com as equações de regressão, ocorreram acréscimos de 0,$68 ; 0,74$ e $0,62 \%$ na altura de planta em função da reposição hídrica aos 30; 60 e 75 DAS, respectivamente. Em geral, cada aumento de $25 \%$ na RH ocorre um incremento de $16,9 \%$ na altura de planta, aos 30 DAS, de 18,5\% aos 60 DAS e de $15,5 \%$ aos 75 DAS, respectivamente. Cunha et al. (2013) observaram que a altura das plantas variam em função do regime hídrico com reduções significativas devido às irrigações com menores lâminas.

Observa-se na Figura 1B aumento linear para DC aos 30, 45, 60 e 75 DAS em função do aumento da RH. Segundo a equação de regressão aos 30, 45, 60 e 75 DAS, ocorreu acréscimos lineares na ordem de 0,35; 0,66; 0,63 e $0,69 \%$ no DC para cada aumento unitário da reposição hídrica, respectivamente.

De acordo com as equações de regressão, para todas as avaliações $(30 ; 45 ; 60$ e 75 DAS) verifica-se um incremento linear no NF, mostrando a importância da irrigação para ampliação da parte aérea do feijoeiro. Segundo as equações (Figura 1C), ocorreu um aumento no NF de 0,$45 ; 1,33 ; 1,04$ e $2,07 \%$ para cada incremento unitário na $\mathrm{RH}$, estimando assim um NF de 9,5; 26,1; 33,9 e 24,3 aos 30; 45; 60 e 75 DAS, respectivamente. Os resultados de NF em feijão caupi obtidos por Nascimento et al. (2004) corroboram com esses resultados, onde a medida que se aumenta a $\mathrm{RH}$, maiores são os aumentos foliares quantitativos.

$\mathrm{Na}$ Figura 1D observa-se a AF em função da reposição hídrica aos 30, 45, 60 e 75 DAS, verificando resultados lineares, onde, as menores médias de $\mathrm{AF}$ registradas foram para a RH de $25 \%$ e as maiores para $100 \%$ RH, assim, quanto maior o estresse hídrico menor é a área foliar. Esses resultados corroboram com os encontrados por Mendes et al. (2007) e Monteiro et al. (2010). Carlesso et al. (2007) verificou que após o início do florescimento, maiores valores de índice de área foliar do feijão são alcançados com progressiva redução das lâminas e aumento da frequência de irrigação. Ainda com relação a Figura 1D, estima-se segundo as equações de regressão, que para cada aumento de $1 \%$ na reposição hídrica ocorre um acréscimo de 0,$9 ; 2,2 ; 11,1$ e $61,7 \%$ na $\mathrm{AF}$ aos 30, 45, 60 e 75\%, respectivamente.
A)

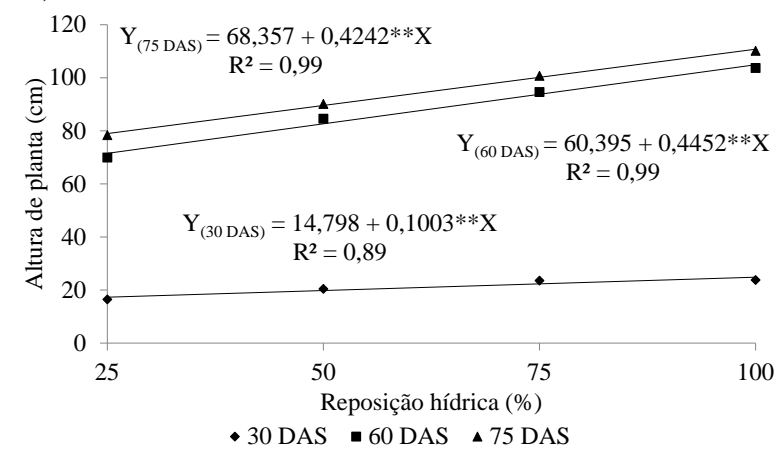

B)

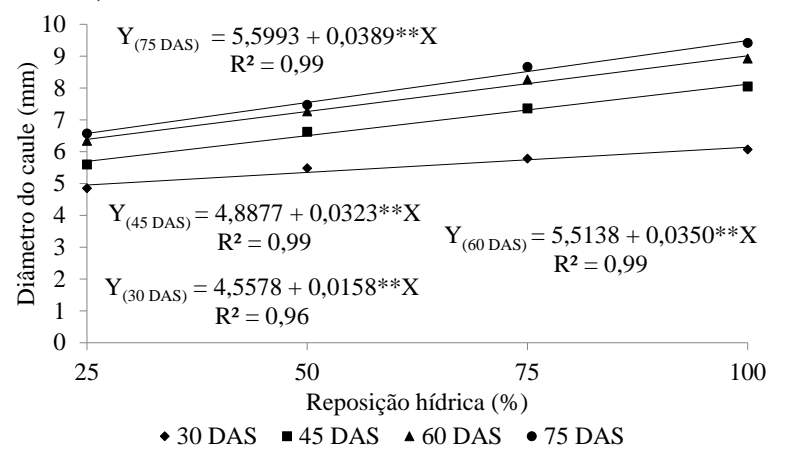


C)

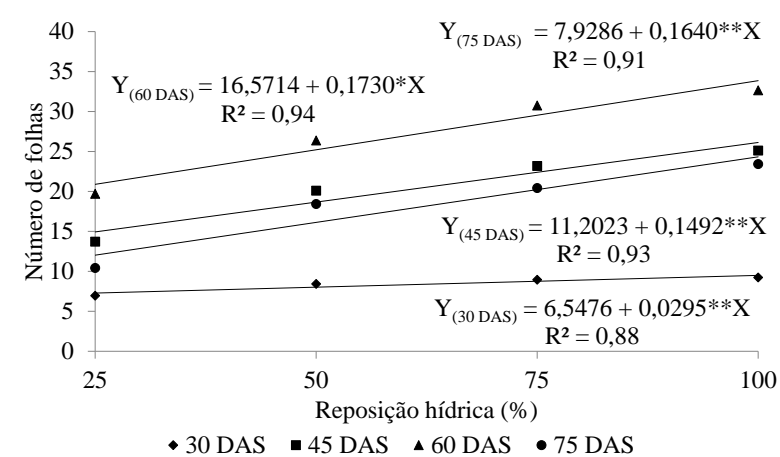

D)

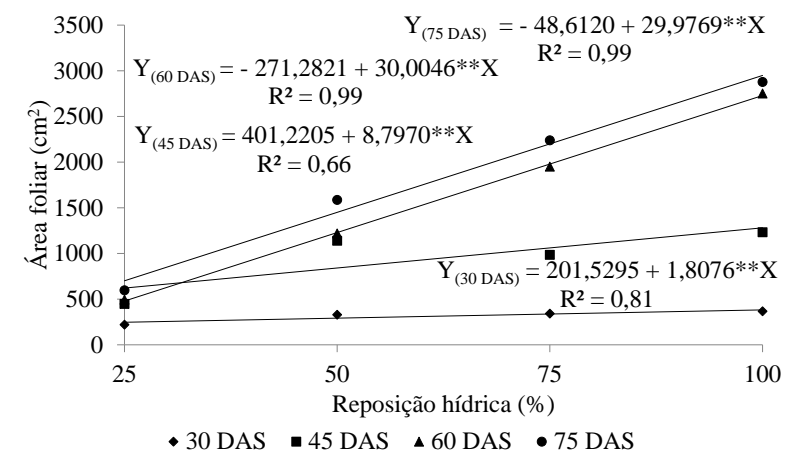

Figura 1. Altura de planta do feijoeiro (A), diâmetro do caule (B), número de folhas (C) e área foliar (D) em função da reposição hídrica (RH) para os dias após semeadura (DAS).

Nascimento et al. (2004) alcançaram resultados de déficit hídrico semelhantes a este para o feijão-caupi, mostrando que nas lâminas de 40, 60 e $80 \%$ de água disponível (AD) houve um decréscimo na altura de planta, sendo o pior resultado obtido para $40 \%$ de AD seguido das 60 e $80 \%$ AD em relação a testemunha.

$\mathrm{Na}$ Figura 2A e B encontra-se o desdobramento da RH dentro de cada tipo de formulação para AP do feijoeiro aos 45 DAS. Observa-se que as formulações F2, F3, F4, F5, F6 e F7 promoveram aumentos lineares na AP; já para a formulação $\mathrm{F} 1$ houve um ajustamento a uma equação quadrática; observou-se assim uma altura máxima de $105,8 \mathrm{~cm}$ com $\mathrm{RH}$ de $62,6 \%$ e aos $100 \%$ de $\mathrm{RH}$ houve um decréscimo de 53,6\% (Figura 2A) quando utilizada a formulação F1. Leal e Prado (2008) verificaram que sob condições de casa de vegetação, as omissões individuais de $\mathrm{N}, \mathrm{P}, \mathrm{K}$ e $\mathrm{Ca}$ foram as mais limitantes para $\mathrm{O}$ crescimento vegetativo do feijoeiro.

Ainda na Figura $2 \mathrm{~A}$ e $\mathrm{B}$, pelas equações de regressão, estima-se que para cada aumento de $1 \%$ na reposição hídrica a um incremento na AP de 2,07; 1,57; 21,$16 ; 2,09 ; 1,74$ e $4,71 \%$ para as formulações F2, F3, F4, F5, F6 e F7, respectivamente. Esses resultados corroboram com os encontrados por Rodrigues (2010), Souza et al. (2003) e Souza et al. (2008) que verificaram que o incremento da adubação elevou a altura de plantas do feijoeiro.
A)

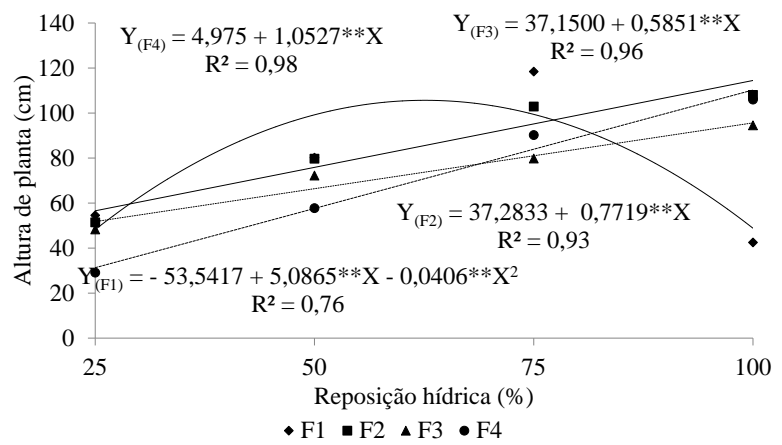

B)

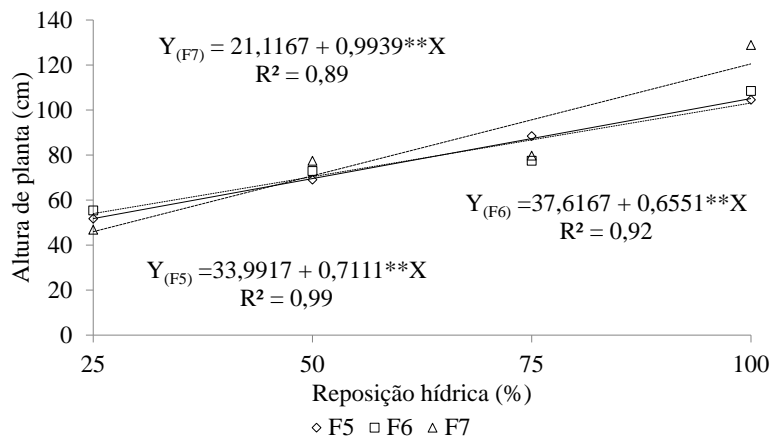

Figura 2. Desdobramento da reposição hídrica dentro de cada tipo de formulação para altura de planta do feijoeiro aos 45 dias após semeadura (DAS) para as formulações F1, F2, F3, F4 (A) e F5, F6 e F7 (B).

Na Tabela 2 verifica-se o resumo do desdobramento das formulações dentro de cada RH para altura de planta aos 45
DAS. Observa-se diferença significativa apenas na RH de $100 \%$, onde a F1 difere estatisticamente de todas as outras 
formulações, sendo a altura de planta $55 \%$ inferior as demais formulações. do feijoeiro verificada nesta formulação

Tabela 2. Desdobramento do tipo de formulação dentro de cada reposição hídrica para altura de planta do feijoeiro aos 45 dias após semeadura (DAS).

\begin{tabular}{|c|c|c|c|c|}
\hline \multirow{3}{*}{ Tipo de Formulaçãa ${ }^{1}$} & \multicolumn{4}{|c|}{ Reposição hídrica (\%) } \\
\hline & 25 & 50 & 75 & 100 \\
\hline & \multicolumn{4}{|c|}{ Altura de planta $(\mathrm{cm})$} \\
\hline F1 - 100:100:100\% de N:P:K & $54,57 \mathrm{a}$ & $80,20 \mathrm{a}$ & $118,4 \mathrm{a}$ & $42,50 \mathrm{~b}$ \\
\hline F2 -50:100:50\% de N:P:K & $51,43 \mathrm{a}$ & $79,73 \mathrm{a}$ & $102,9 \mathrm{a}$ & $108,03 \mathrm{a}$ \\
\hline F3 - 200:100:200\% de N:P:K & $48,30 \mathrm{a}$ & $72,23 \mathrm{a}$ & $79,80 \mathrm{a}$ & $94,53 \mathrm{a}$ \\
\hline F4 -50:100:100\% de N:P:K & $29,10 \mathrm{a}$ & $57,75 \mathrm{a}$ & $90,23 \mathrm{a}$ & $106,00 \mathrm{a}$ \\
\hline F5 - 200:100:100\% de N:P:K & $51,73 \mathrm{a}$ & $69,05 \mathrm{a}$ & $88,43 \mathrm{a}$ & $104,53 \mathrm{a}$ \\
\hline F6 - 100:100:50\% de N:P:K & $55,40 \mathrm{a}$ & $72,90 \mathrm{a}$ & $77,47 \mathrm{a}$ & $108,47 \mathrm{a}$ \\
\hline F7 - 100\%:100\%:200\% de N:P:K & $46,83 \mathrm{a}$ & $77,47 \mathrm{a}$ & $79,73 \mathrm{a}$ & $128,90 \mathrm{a}$ \\
\hline
\end{tabular}

${ }^{1}$ Médias seguidas pela mesma letra na coluna não diferem entre si pelo teste de Tukey a $5 \%$ de probabilidade.

Para as médias das formulações do diâmetro do caule apenas as formulações F1 e F7 diferiram entre si, sendo que a F7 teve o maior crescimento em DC, enquanto o F1 obteve o pior desempenho (Tabela 3). Rodrigues (2010) avaliando níveis de NPK no cultivo de feijoeiro detectou que quanto mais aumenta as doses das adubações mais tem-se o aumento do DC, sendo que no estudo do mesmo autor o aumento constante aconteceu entre os 50 e $125 \%$ de doses de NPK.

Abordando as médias das formulações (Tabela 3) em função dos 15, 30, 45, 60 e 75
DAS verificou-se que não houve nenhuma diferença significativa para a altura de planta e área foliar. Para o número de folhas observouse diferença significativa apenas aos 30 DAS, onde na F2 observou-se uma redução de aproximadamente $1 \%$ nesta variável. $\mathrm{Na}$ fase de florescência e enchimento de grãos do feijoeiro os números de folhas foram iguais. Os dados apresentados são semelhantes com os encontrados por Lima et al. (2001) e Rodrigues (2010) que não obtiveram resultados significativos para este parâmetro.

Tabela 3. Médias para altura de planta, diâmetro do caule, número de folhas e área foliar do feijoeiro submetido a diferentes tipos de formulações de adubação aos 15, 30, 45, 60 e 75 dias após semeadura (DAS).

\begin{tabular}{lccccc}
\hline \multirow{2}{*}{ Formulação } & \multicolumn{5}{c}{ Médias $^{1}$} \\
\cline { 2 - 6 } F1 - 100:100:100\% de N:P:K & $7,31 \mathrm{a}$ & $20,77 \mathrm{a}$ & $73,92 \mathrm{a}$ & $86,77 \mathrm{a}$ & $95,00 \mathrm{a}$ \\
F2 -50:100:50\% de N:P:K & $7,24 \mathrm{a}$ & $21,02 \mathrm{a}$ & $85,52 \mathrm{a}$ & $85,45 \mathrm{a}$ & $91,33 \mathrm{a}$ \\
F3 - 200:100:200\% de N:P:K & $6,87 \mathrm{a}$ & $22,14 \mathrm{a}$ & $73,71 \mathrm{a}$ & $83,75 \mathrm{a}$ & $89,41 \mathrm{a}$ \\
F4 -50:100:100\% de N:P:K & $7,07 \mathrm{a}$ & $21,04 \mathrm{a}$ & $70,77 \mathrm{a}$ & $93,67 \mathrm{a}$ & $100,2 \mathrm{a}$ \\
F5 - 200:100:100\% de N:P:K & $7,24 \mathrm{a}$ & $20,79 \mathrm{a}$ & $78,43 \mathrm{a}$ & $90,19 \mathrm{a}$ & $95,25 \mathrm{a}$ \\
F6- 100:100:50\% de N:P:K & $7,28 \mathrm{a}$ & $20,70 \mathrm{a}$ & $78,55 \mathrm{a}$ & $88,78 \mathrm{a}$ & $97,08 \mathrm{a}$ \\
F7-100\%:100\%:200\% de N:P:K & $7,15 \mathrm{a}$ & $21,00 \mathrm{a}$ & $83,23 \mathrm{a}$ & $88,91 \mathrm{a}$ & $95,83 \mathrm{a}$ \\
\hline & & Diâmetro do caule $(\mathrm{mm})$ & \\
F1 - 100:100:100\% de N:P:K & $3,07 \mathrm{a}$ & $5,51 \mathrm{a}$ & $6,85 \mathrm{a}$ & $7,28 \mathrm{a}$ & $7,48 \mathrm{~b}$ \\
F2-50:100:50\% de N:P:K & $3,08 \mathrm{a}$ & $5,52 \mathrm{a}$ & $6,71 \mathrm{a}$ & $7,55 \mathrm{a}$ & $8,06 \mathrm{ab}$ \\
F3-200:100:200\% de N:P:K & $3,03 \mathrm{a}$ & $5,61 \mathrm{a}$ & $7,03 \mathrm{a}$ & $7,92 \mathrm{a}$ & $7,96 \mathrm{ab}$ \\
F4 -50:100:100\% de N:P:K & $3,01 \mathrm{a}$ & $5,59 \mathrm{a}$ & $6,70 \mathrm{a}$ & $7,78 \mathrm{a}$ & $8,26 \mathrm{ab}$
\end{tabular}


Morais et al.

\begin{tabular}{lrrrrr} 
F5 - 200:100:100\% de N:P:K & $3,07 \mathrm{a}$ & $5,61 \mathrm{a}$ & $6,89 \mathrm{a}$ & $7,89 \mathrm{a}$ & $8,16 \mathrm{ab}$ \\
F6 - 100:100:50\% de N:P:K & $3,01 \mathrm{a}$ & $5,32 \mathrm{a}$ & $6,92 \mathrm{a}$ & $7,35 \mathrm{a}$ & $7,77 \mathrm{ab}$ \\
F7 - 100\%:100\%:200\% de N:P:K & $3,03 \mathrm{a}$ & $5,64 \mathrm{a}$ & $7,22 \mathrm{a}$ & $8,09 \mathrm{a}$ & $8,50 \mathrm{a}$ \\
\hline & & \multicolumn{4}{c}{ Número de folhas } \\
F1 - 100:100:100\% de N:P:K & & $8,91 \mathrm{a}$ & $19,33 \mathrm{a}$ & $24,25 \mathrm{a}$ & $18,25 \mathrm{a}$ \\
F2 -50:100:50\% de N:P:K & & $8,12 \mathrm{~b}$ & $21,08 \mathrm{a}$ & $26,91 \mathrm{a}$ & $19,00 \mathrm{a}$ \\
F3 - 200:100:200\% de N:P:K & & $8,66 \mathrm{a}$ & $22,12 \mathrm{a}$ & $26,00 \mathrm{a}$ & $17,16 \mathrm{a}$ \\
F4 -50:100:100\% de N:P:K & & $8,25 \mathrm{a}$ & $20,33 \mathrm{a}$ & $25,33 \mathrm{a}$ & $17,00 \mathrm{a}$ \\
F5 - 200:100:100\% de N:P:K & & $8,33 \mathrm{a}$ & $20,75 \mathrm{a}$ & $29,08 \mathrm{a}$ & $18,75 \mathrm{a}$ \\
F6 - 100:100:50\% de N:P:K & & $8,20 \mathrm{a}$ & $19,91 \mathrm{a}$ & $30,41 \mathrm{a}$ & $21,75 \mathrm{a}$ \\
F7 - 100\%:100\%:200\% de N:P:K & & & Área foliar $\left(\mathrm{cm}^{2}\right)$ & $29,66 \mathrm{a}$ & $15,33 \mathrm{a}$ \\
\hline & & & & \\
F1 - 100:100:100\% de N:P:K & $104,34 \mathrm{a}$ & $323,61 \mathrm{a}$ & $726,00 \mathrm{a}$ & $1411,95 \mathrm{a}$ & $1561,19 \mathrm{a}$ \\
F2 -50:100:50\% de N:P:K & $104,33 \mathrm{a}$ & $333,80 \mathrm{a}$ & $1387,6 \mathrm{a}$ & $1693,08 \mathrm{a}$ & $2085,90 \mathrm{a}$ \\
F3 - 200:100:200\% de N:P:K & $97,14 \mathrm{a}$ & $291,83 \mathrm{a}$ & $1001,8 \mathrm{a}$ & $1310,40 \mathrm{a}$ & $1564,32 \mathrm{a}$ \\
F4 -50:100:100\% de N:P:K & $101,16 \mathrm{a}$ & $320,60 \mathrm{a}$ & $896,63 \mathrm{a}$ & $1594,43 \mathrm{a}$ & $1722,04 \mathrm{a}$ \\
F5 - 200:100:100\% de N:P:K & $99,55 \mathrm{a}$ & $377,20 \mathrm{a}$ & $817,15 \mathrm{a}$ & $1514,73 \mathrm{a}$ & $1741,95 \mathrm{a}$ \\
F6 - 100:100:50\% de N:P:K & $105,39 \mathrm{a}$ & $285,17 \mathrm{a}$ & $928,26 \mathrm{a}$ & $1959,61 \mathrm{a}$ & $2473,35 \mathrm{a}$ \\
F7 - 100\%:100\%:200\% de N:P:K & $101,52 \mathrm{a}$ & $269,30 \mathrm{a}$ & $899,81 \mathrm{a}$ & $1743,83 \mathrm{a}$ & $1625,83 \mathrm{a}$ \\
\hline
\end{tabular}

${ }^{1}$ Médias seguidas pela mesma letra na coluna não diferem entre si pelo teste de Tukey a 5\% de probabilidade.

De acordo com a tabela 4 houve diferença significativa a $1 \%$ de probabilidade para número de vargens por planta (NVP) e peso de grãos por planta (PGP) em função da $\mathrm{RH}$, porém, o fator $\mathrm{F}$ e a interação RH x F não apresentaram diferenças significativas.

Tabela 4. Resumo da ANAVA para número de vagens por planta (NVP) e produção de grãos por planta (PGP) do feijoeiro submetido a diferentes reposições hídricas e tipos de formulações de adubação.

\begin{tabular}{|c|c|c|c|}
\hline \multirow{2}{*}{ Fonte Variação } & \multirow{2}{*}{ GL } & \multicolumn{2}{|c|}{ Quadrados Médio } \\
\hline & & $\mathrm{NVP}^{1}$ & $\mathrm{PGP}^{2}$ \\
\hline RH & 3 & $9,26^{* *}$ & $15,16^{* * *}$ \\
\hline Bloco & 2 & $0,39^{\text {ns }}$ & $0,47^{\mathrm{ns}}$ \\
\hline Resíduo a & 6 & 0,63 & 1,15 \\
\hline $\mathrm{F}$ & 6 & $0,26^{\mathrm{ns}}$ & $0,91^{\mathrm{ns}}$ \\
\hline $\mathrm{RH} \times \mathrm{F}$ & 18 & $0,20^{\mathrm{ns}}$ & $0,53^{\mathrm{ns}}$ \\
\hline Resíduo b & 48 & 0,19 & 0,42 \\
\hline $\mathrm{CV}$ a $(\%)$ & & 18,91 & 20,74 \\
\hline \multirow[t]{2}{*}{$\mathrm{CV} \mathrm{b}(\%)$} & & 10,50 & 12,51 \\
\hline & & \multicolumn{2}{|c|}{ Médias $^{2}$} \\
\hline \multicolumn{4}{|l|}{ Formulação } \\
\hline F1 - 100:100:100\% de N:P:K & & 16,25 & 24,52 \\
\hline F2 -50:100:50\% de N:P:K & & 19,50 & 31,21 \\
\hline F3 - 200:100:200\% de N:P:K & & 17,41 & 25,23 \\
\hline F4 -50:100:100\% de N:P:K & & 18,91 & 25,52 \\
\hline F5 - 200:100:100\% de N:P:K & & 17,58 & 23,20 \\
\hline F6 - 100:100:50 \% de N:P:K & & 20,16 & 30,71 \\
\hline F7 - 100\%:100\%:200\% de N:P:K & & 19,08 & 28,02 \\
\hline
\end{tabular}


ns teste $\mathrm{F}$ não significativo a $5 \%,{ }^{*} \mathrm{e}^{* * *}$ significativo a 5 a $1 \%$ de probabilidade, respectivamente. GL - Grau de liberdade. RH - Reposição hídrica. F - Tipo de formulação. RH x F - Interação RH x F. CV - Coeficiente de variação. ${ }^{1}$ Dados transformados em Raiz de X. ${ }^{2}$ Dados transformados em Raiz de $\mathrm{X}+1$.

Segundo a equação de regressão (Figura $3 \mathrm{~A})$, estima-se que houve um incremento no número de vagens por planta de $51 \%$ nas plantas com $100 \%$ da $\mathrm{RH}$ em relação as com $\mathrm{RH}$ de $25 \%$, gerando um incremento de $2,1 \%$ no NVP para cada aumento unitário da RH. Com relação ao NVP Monteiro et al. (2010) e Torres et al. (2013) constataram também um aumento proporcional de vagens no feijoeiro quando se aumenta a RH em até $100 \%$. Tagliaferre et al. (2013) encontraram um comportamento quadrático para o NVP de feijão caupi, onde na lâmina de irrigação de 498,66 mm verificou o melhor resultado com média de 16,6 vagens por planta, o aumento da

A)

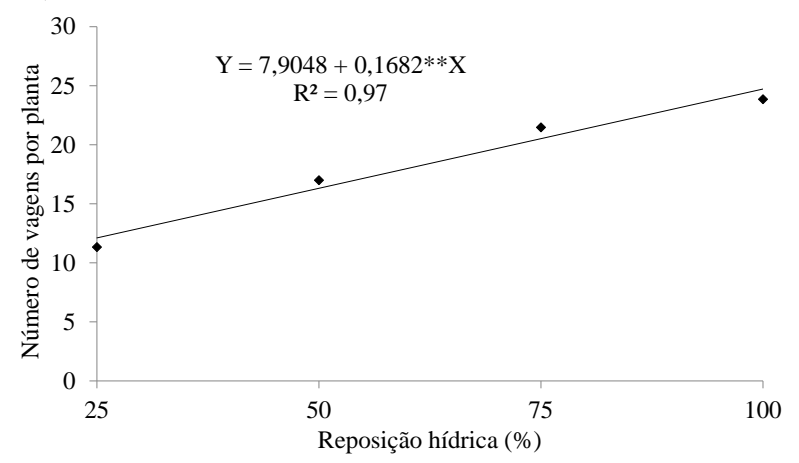

lâmina proporcionou uma queda neste parâmetro avaliado.

Os resultados a produção de grãos por planta indicam que utilizando uma reposição hídrica de 25, 50, 75 e 100\% obtém uma produção estimada, segundo a equação de regressão (Figura $3 \mathrm{~B}$ ), de 16,$97 ; 23,60 ; 30,24$ e 38,88 g planta $^{-1}$, respectivamente, gerando um aumento de $2,6 \%$ para cada aumento de $1 \%$ na reposição hídrica. Estes resultados corroboram com os de Mendes et al. (2007) que mostram que quanto maior o estresse hídrico menor a quantidade de grãos em uma planta.

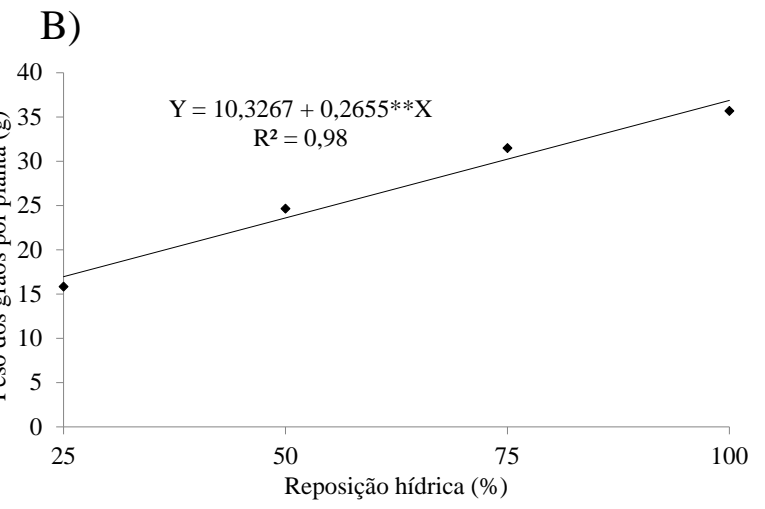

Figura 3. Número de vagens por planta (A) e produção de grãos por planta (B) do feijoeiro em função da reposição hídrica.

\section{CONCLUSÕES}

A melhor formulação de adubação foi a de 100\%:100\%:200\% de NPK, a qual obteve as melhores médias nos parâmetros diâmetro do colmo e número de folha.

Quanto maior a disponibilidade de água para o feijoeiro melhor será os seus parâmetros quantitativos de crescimento (altura de planta, diâmetro do colmo, número de folha e área foliar) e produção (número de vagens por planta e produção de grãos por planta).

\section{AGRADECIMENTOS}

Os autores agradecem ao Ministério da Ciência e Tecnologia (MCT), ao Conselho Nacional de Desenvolvimento Científico e Tecnológico (CNPq), à Coordenação de Aperfeiçoamento de Pessoal de Nível Superior (Capes), à Fundação de Amparo à Pesquisa do Estado de Goiás (FAPEG) e ao Instituto Federal Goiano - Campus Rio Verde, pelo apoio financeiro e estrutural.

\section{REFERÊNCIAS BIBLIOGRÁFICAS}

CARVALHO, M.A.C.; ARF, O.; SÁ, M.E.; BUZETTI, S.; SANTOS, N.C.B.; BASSAN, D.A. Produtividade e qualidade de sementes 
de feijoeiro (Phaseolus vulgaris L.) sob influência de parcelamentos e fontes de nitrogênio. Revista Brasileira de Ciência do Solo, v.25, p.617-624, 2001.

CUNHA, P. C. R. da; SILVEIRA, P. M. da; NASCIMENTO, J. L. do; ALVES JÚNIOR, J. Manejo da irrigação no feijoeiro cultivado em plantio direto. Campina Grande, PB, UAEA/UFCG. Revista Brasileira de Engenharia Agrícola e Ambiental, v.17, n.7, p.735-742, 2013.

DAMIANI, C. B. Avaliação de cultivares crioulas de feijão (Phaseolus vulgaris L.) resistentes ao caruncho (Acanthoscelides obtectus Say). Dissertação. Universidade do Estado de Santa Catarina - UDESC. Programa de Pós-graduação em Produção Vegetal, Lages - SC, 80p., 2011.

EMBRAPA. Sistema brasileiro de classificação de solos. Empresa Brasileira de Pesquisa Agropecuária. Centro Nacional e Pesquisa em Solos. Brasília, 306p. 2006.

FIGUEIREDO, E. da S.; SANTOS, M. E. dos; GARCIA, A. Modelos de determinação não destrutivo da área foliar do feijoeiro comum (Phaseolus vulgaris L.). Fundação Educacional de Ituverava. Nucleus, v.9, n.1, abr. 2012

FIGUEIREDO, M. G. de; FRIZZONE, J.A.; PITELLI, M.M.; REZENDE, R. Lâmina ótima de irrigação do feijoeiro, com restrição de água, em função do nível de aversão ao risco do produtor função do nível de aversão ao risco do produtor. Acta Scientiarum Agronomy, v. 30, n. 1, p. 81-87, 2008.

FIGUEIREDO, M. G. de; PITELLI, M. M.; FRIZZONE, J. A.; DETOMINI, E. R. Escolha da lâmina ótima de irrigação para feijão, de acordo com o nível de aversão ao risco por parte do produtor. Administração rural e gestão do agronegócio. XLIV CONGRESSO DA SOBER. Sociedade Brasileira de Economia e Sociologia Rural, Fortaleza -
Ceará. ESALQ/USP Piracicaba - SP - Brasil, p.12, 2006.

FIGUERÊDO, S.F.; POZZEBON, E.J.; FRIZZONE, J.A.; AZEVEDO, J.A. DE; GUERRA, A.F.; SILVA, E.M. DA. Gerenciamento da irrigação do feijoeiro baseado em critérios técnicos e econômicos no cerrado. Revista Irriga, vol. 13, n. 3, p. 378391, 2008.

GOMES, E.P.; JORDAN, R.A.; MOTOMIYA, A.V.A.; PADUA, J.B.; BISCARO, G.A.; GEISENHOFF, L.O. Análise econômica e viabilidade energética da cultura do feijoeiro comum sob irrigação. Revista Brasileira Engenharia Agrícola e Ambiental, v.17, n.8, p.835-842, 2013.

LEAL, R. M.; PRADO, R. de M. Desordens nutricionais no feijoeiro por deficiência de macronutrientes, boro e zinco. Recife, PE, UFRPE. Revista Brasileira de Ciências Agrárias v.3, n.4, p.301-306, 2008.

LIMA, E. V.; ARAGÃO, C.A.; MORAIS, O. M.; TANAKA, R.; GRASSI FILHO, H. ADUBAÇÃO NK no desenvolvimento e na concentração de macronutrientes no florescimento do feijoeiro. Scientia Agricola, v.58, n.1, p.125-129, jan./mar. 2001.

MENDES, R.M.S.; TÁVORA, F.J.A.F.; PITOMBEIRA, J.B.; NOGUEIRA, R.J.M.C. Relações fonte-dreno em feijão-de-corda submetido à deficiência hídrica. Revista Ciência Agronômica, v.38, n.1, p.95-103, 2007.

MONTEIRO, P.F.C., ANGULO FILHO, R.; MONTEIRO, R.O.C. Efeitos da irrigação e da adubação nitrogenada sobre as variáveis agronômicas da cultura do feijão. Revista Irriga, v. 15, n. 4, p. 386-400, 2010.

MOUSINHO, F.E.P., ANDRADE JÚNIOR, A.S. de; FRIZZONE, J.A. Viabilidade econômica do cultivo irrigado do feijão-caupi no Estado do Piauí. Acta Scientiarum Agronomy v. 30, n. 1, p. 139-145, 2008. 
NASCIMENTO, J.T.; PEDROSA, M.B.; TAVARES SOBRINHO, J. Efeito da variação de níveis de água disponível no solo sobre o crescimento e produção de feijão caupi, vagens e grãos verdes. Horticultura Brasileira, Brasília, v.22, n.2, p.174-177, abril-junho 2004.

OLIVEIRA, I. P.; ARAUJO, R. S.; DUTRA, L. G. Nutrição mineral e fixação biológica de nitrogênio. In: ARAÚJO, R. S.; RAVA, C.; STONE, L. F.; ZIMMERMANN, M. J. O. Cultura do feijoeiro comum no Brasil. Piracicaba: Potafos, 1996. p. 169-221.

RODRIGUES, J. Trichoderma spp. associado a níveis de adubações NPK no patossistema Sclerotinia sclerotiorum - feijão. Santa Maria. Dissertação. Centro de Ciências Rurais, Universidade Federal de Santa Maria. 2010, 84p.

SCHMIDT, E.W; VALIATI, M.I. Avaliação do manejo de irrigação para a cultura de feijão (Phaseolus vulgaris) irrigada por pivô central na agrícola Wehrmann em Cristalina-GO. Campo Digital, v.1, n.1, p.23-31, jul./dez. 2006.

SILVA, T.R.B.; SORATTO, R.P.; CHIDI, S.N.; ARF, O.; SÁ, M.E.; BUZETTI, S. Doses e épocas de aplicação de nitrogênio em cobertura na cultura do feijoeiro de inverno. Cultura agronômica, v.9, p.1-17, 2000.

SOUZA, A.B. de; ANDRADE, M.J.B. de; MUNIZ, J.A. Altura de planta e componentes do rendimento do feijoeiro em função de população de plantas, adubação e calagem. Ciência e Agrotecnologia, Lavras. V.27, n.6, p.1205-1213, nov./dez., 2003.

SOUZA, A.B. de; ANDRADE, M.J.B. de; VIEIRA, N.M.B.; ALBUQUERQUE, A. de. Densidades de semeadura e níveis de NPK e calagem na produção do feijoeiro sob plantio convencional, em Ponta Grossa, Paraná. Pesquisa Agropecuária Tropical, v. 38, n. 1, p. 39-43, 2008.

TAGLIAFERRE, C. SANTOS, T.J.; SANTOS, L.C; SANTOS NETO, I.J. dos; ROCHA, F.A.; PAULA, A. de. Características agronômicas do feijão caupi inoculado em função de lâminas de irrigação e de níveis de nitrogênio. Revista Ceres. vol.60, n.2, p. 242248, 2013.

TORRES, J.L.R.; SANTANA, M.J.; PIZOLATO NETO, A.; PEREIRA, M.G.; VIEIRA, D.M.S. Produtividade de feijão sobre lâminas de irrigação e coberturas de solo. Bioscience Journal, v. 29, n. 4, p.833841, 2013. 